\title{
ESTUDOS
}

\section{As concepções de professores de um curso a distância sobre o papel do fórum on-line}

Erlinda M. Batista Shirley T. Gobara

\section{Resumo}

Focaliza o papel do fórum on-line na concepção dos professores que atuaram em um curso de pós-graduação lato sensu a distância, realizado em uma instituição pública de ensino superior. Os fóruns on-line associados a cursos são meios de interações assíncronas entre professores e alunos. Os fóruns das disciplinas do curso investigado foram observados e os sujeitos (professores e alunos), entrevistados no período de agosto de 2004 a junho de 2005. As análises desses dados se basearam na noção de situação didática e contrato didático de Brousseau (1996, apud Silva, B., 2002), nos conceitos de interação social e aprendizagem de Vigotsky (2000) e nas idéias sobre a formação do professor de educação a distância (EaD), discutidas por Belloni (2001). Essas análises foram complementadas com discussões sobre a formação de comunidades de aprendizagem on-line e o papel do professor e do aluno virtual, segundo Palloff e Pratt (2004), e sobre os conceitos de ambientes digitais de aprendizagem de Almeida (2003). Conclui que as concepções de fórum dos professores do curso mencionado são oriundas de formação e práticas presenciais e que há poucos incentivos para atualização permanente desses profissionais. Constatou-se a necessidade de investimentos do poder público na formação continuada dos professores de $\mathrm{EaD}$, que contribuam para mudanças de suas concepções e resultem em transformações de suas ações no ambiente virtual, necessárias para a sociedade da informação.

Palavras-chave: fórum on-line; interação; educação a distância.

\section{Abstract \\ The conceptions of distance course teachers on the role of the on-line forum}

This article reports a case study, which focused the role of the on-line forum in the conception of the teachers who worked in a post-graduation lato sensu distance course held by a public university. The on-line forums associated with courses are means of asynchronous interactions between teachers and students. The forums of the subjects of the course at issue were observed and the subjects (teachers and students) were interviewed in the period between August 2004 and July 2005. The analyses of these data were based on Brousseau's notion of didactical situation and didactical contract (1996), on Vigotsky's concepts of social interaction and learning (2000), and on the ideas about the formation of distance education teachers (EaD), discussed by Belloni (2001). These analyses were complemented with discussions about the formation of on-line learning communities and the roles of virtual teacher and students according to Palloff and Pratt (2004), and 
about Almeida's concepts of digital learning environment (2003). It may be concluded that the conceptions of forum that the teachers of the aforementioned course have are originated from presence formation and practice and that there is little incentive for bringing these professionals up to date. It was concluded that there is a need for State investments in the continuous formation of EaD teachers, so as to contribute to changes in their conceptions and to bring about transformations of their actions in the virtual environment, aspects necessary for the information society.

Keywords: on-line forum; interaction; distance education.

\section{Introdução}

Este trabalho apresenta as concepções dos professores sobre o papel do fórum online em cursos a distância. Esses professores atuaram na terceira edição do curso de pós-graduação lato sensu a distância, oferecido por uma instituição federal de ensino superior no período de fevereiro de 2004 a junho de 2005.

No levantamento bibliográfico realizado, verificou-se que não há muitas pesquisas sobre a utilização do fórum na literatura. Partindo-se dessa constatação, a questão básica que originou o estudo foi: quais as concepções de fórum on-line em um curso a distância? Além dessa, questões complementares foram analisadas na pesquisa realizada, a saber:

1) De que forma a construção do conhecimento em um curso a distância pode ser realizada usando-se o fórum on-line?

2) Qual o perfil do professor usuário do fórum on-line no curso observado?

3) Quais as concepções dos professores do curso sobre o fórum on-line?

Entre as respostas para as questões acima especificadas, buscou-se ressaltar as relacionadas com as concepções de fórum on-line dos professores, objeto deste artigo, considerando-se as informações obtidas nas entrevistas e nas observações de suas práticas pedagógicas ao longo do período de realização do curso investigado. Além dos professores, os alunos também foram entrevistados e observados em suas participações nos fóruns on-line das disciplinas oferecidas no curso.

Este artigo se justifica pela relevância e pela necessidade de se discutir temáticas que tratam da utilização de tecnologias educacionais em cursos a distância, particularmente aquelas que tratam dos meios que possibilitam a interação entre o professor e o aluno e/ou entre alunos intermediada pelos ambientes on-line e off-line, ${ }^{1}$ neste caso, o fórum.

As concepções de fórum on-line apresentadas pelos professores investigados, de uma forma geral, identificam-no como uma ferramenta de comunicação e/ou um repositório de atividades. Essas concepções limitam as possibilidades de interação entre professor-aluno e entre alunos e interferem na qualidade da interação entre eles. Baseado nesse resultado, este estudo faz uma reflexão, não exaustiva, ressaltando a importância das concepções sobre o papel do fórum on-line para os cursos a distância e sugere o fórum como um espaço virtual de interação, constituindo-se um ambiente potencialmente favorável à construção do conhecimento. Este estudo visa contribuir para a formação de docentes que atuam e que vão atuar na educação a distância (EaD).

\section{O fórum on-line e a educação a distância}

A palavra fórum atualmente tem diferentes significados, a partir do contexto a que se refere. Alguns exemplos são: fórum jurídico, fórum humorístico, fórum de discussão, entre outros.

O significado original dessa palavra, segundo o Novo Aurélio, vem do latim forum - algo que permite o movimento, ou apresenta movimento - e do grego phorós, "carregar", "transportar", “apresentar certo movimento" (Ferreira, 1999, p. 932).

Entre os diferentes significados que essa palavra pode assumir, na versão de Houaiss (2004, p. 352) fórum é definido como "reunião, congresso, conferência para debate de um tema". De acordo com o dicionário on-line da Columbia, por

\footnotetext{
Moran (2006) define on-line como a comunicação em tempo real e off-line como a comunicação em tempos diferentes.
} 
2 "a public meeting place for open discussion". Disponível em: http:// www.thefreedictionary.com/ Forums. Acesso em: $1^{\circ} \mathrm{de}$ agosto de 2006.

${ }^{3}$ Comunidade de aprendizagem on-line é definida por Palloff e Pratt (2004) como um grupo de pessoas, professores, alunos e coordenação com um objetivo comum de realizar uma aprendizagem permeada por uma prática reflexiva, com políticas (diretrizes de curso) comuns um sistema computacional (um site onde se hospeda o curso on-line)

4 Barsotti (2002) define artefato como uma ferramenta que medeia determinada atividade e que conecta uma pessoa não apenas com o mundo dos objetos, mas também com outras pessoas.

5 "A teoria da atividade é um enfoque interdisciplinar para as ciências humanas, que se constitui em uma linha de teorização e pesquisa originada na escola de pensamento da psicologia cognitivista históricocultural com Vigotsky, Leontiev e Luria entre as décadas de 20 e 30." (Barsotti, 2002, p. 9).

6 "tudo o que é utilizado pelo homem para representar, evocar, ou tornar presente o que está ausente constitui um signo: a palavra, o desenho, os símbolos" (Fontana; Cruz, 1997, apud Silva, L., 2004, p. 37) exemplo, fórum significa um encontro público para discussão aberta. ${ }^{2}$ Baseado em definições como as duas últimas, surgiram os chamados fóruns de discussão, disponibilizados como uma ferramenta para ambientes virtuais, destinados a promover debates on-line e off-line.

No contexto do ambiente virtual, alguns artigos referentes à informática educativa tratam o fórum como um espaço de discussão e debates para assuntos de interesse comum aos membros de um determinado grupo.

Para Silva (2006), fórum de discussão é a área de interação assíncrona onde os participantes podem trocar opiniões e debater temas propostos - "provocações".

Segundo Moran (2006, p. 1), pode haver dois tipos de fórum: os fóruns gerais, que se destinam a todos e podem ser organizados em grupos para discutir assuntos dos respectivos interesses, e os fóruns de grupos, que podem ser abertos para todos ou só para uma equipe, dependendo do grupo e da atividade. Para ambos os tipos, "um fórum previamente realizado é um ambiente virtual de aprendizagem, quando utilizado para atividades de apoio ao professor".

Almeida (2003, p. 5) considera o fórum on-line um recurso dentro de um ambiente virtual de aprendizagem: "Os recursos dos ambientes digitais de aprendizagem são basicamente os mesmos existentes na Internet (correio, fórum, ...)."

$\mathrm{Na}$ abordagem de recursos de aprendizagem on-line, Preece (2000, apud Palloff, Pratt, 2004, p. 37) observa que se os recursos utilizados on-line tiverem apenas a função de "transmitir informação aos alunos, não se poderá considerar que a sala de aula on-line constitui uma comunidade de aprendizagem on-line". ${ }^{3}$

Fórum on-line como um recurso computacional utilizado por professores e alunos em atividades interativas com interesses comuns para atingir um determinado objetivo pode ser, também, considerado como um artefato. ${ }^{4}$

$\mathrm{O}$ fórum on-line analisado como um artefato computacional fundamenta-se na teoria da atividade. ${ }^{5}$ De acordo com essa teoria, o artefato contempla a necessidade de relacionar as atividades características de um ambiente virtual com o desenvolvimento das atividades humanas e criativas. Para Barsotti (2002, p. 10),
A teoria da atividade toma como unidade de análise um sistema coletivo de atividade mediada por artefatos e orientada para um objeto. Nesse enfoque, a unidade de análise é o sistema de atividades que tem como elementos ... os artefatos mediadores, o objeto, o sujeito, as regras, a comunidade e a divisão do trabalho.

Segundo Barsotti (2002, p. 13), na teoria da atividade os artefatos "desempenham o papel de mediadores do pensamento e comportamento humanos".

Esses mediadores, numa perspectiva histórico-cultural a partir das idéias de Vigotsky (2000), constituem instrumentos (técnicos e ferramentas) e $\operatorname{signos}^{6}$ (especialmente a linguagem). Ele afirma:

Todas as funções psíquicas superiores são processos mediados, e os signos constituem o meio básico para dominá-las e dirigi-las. O signo mediador é incorporado à sua estrutura como uma parte indispensável, na verdade a parte central do processo como um todo (p. 70).

Pode-se afirmar que os signos (especialmente a linguagem verbal escrita ou falada) e os instrumentos (em particular o fórum on-line) são mediadores das funções psíquicas superiores do indivíduo.

Para Silva, L. (2004, p. 37), "instrumentos e signos são meios que orientam o comportamento humano de diferentes maneiras, e que permitem ao indivíduo controlar e transformar o ambiente físico e social do qual ele é parte integrante, como também controlar e transformar seu próprio comportamento".

O fórum on-line não deve ser utilizado como um fim em si, mas como um instrumento mediador entre professores e alunos e entre os próprios alunos na busca do objeto "conhecimento". Nesse sentido, o seu uso deve ter a função de gerar um produto, o conhecimento, pela criação de um debate coletivo, de um texto coletivo, de uma discussão intelectual a respeito de determinado tema de uma disciplina, sob a orientação e cooperação de um professor ou de um aluno, parceiro no curso.

A utilização do fórum on-line possibilita uma flexibilidade de espaço e de tempo dos sujeitos envolvidos no curso. Ele pode armazenar o objeto, o conhecimento, as atividades, as discussões coletivas, o texto coletivo e mediar as trocas 
de informações entre os seus usuários, professores e alunos, em espaços e tempos diferentes.

O fórum on-line, no contexto da pesquisa realizada, foi considerado como um ambiente virtual de ensino e aprendizagem cujo papel principal é o de servir como um meio que possibilita interações síncronas e ou assíncronas entre os elementos do sistema didático professor, aluno e o saber - (Chevallard, 2001) e que também comporta relações sociais, linguagens e informações caracterizadas pela historicidade dos indivíduos presentes nesse meio. É através desse meio que se estabelecem as relações e as interações entre os sujeitos desse sistema (os alunos, professores e coordenação do curso), promovendo-se discussões e debates coletivos, independentemente do tempo e espaço onde estão localizados, com vista à construção do conhecimento.

O fórum on-line de um curso a distância, além de ser um instrumento que funciona como um artefato em um espaço virtual de aprendizagem, possui também uma função comunicacional: a de um repositório de informações. Entretanto, o principal papel do fórum deve ser o de servir como um mediador, um meio preparado pelo professor, para que ocorram as interações entre o(s) professor(es) e os alunos e entre os próprios alunos para promover a aprendizagem. Esse meio deve ser transparente e se assemelhar ao ambiente físico de uma sala de aula concreta; um meio em que as interações realizadas permitam o compartilhamento e a apreensão do novo conhecimento por aqueles que o buscam.

Nessa visão, em que o fórum é considerado um artefato, as ações do professor são, também, relevantes. Almeida (2003, p. 72) afirma:

Para o docente-formador intervir nesse processo, é preciso que ele assuma concomitantemente diversos papéis, tais como: mediador, observador e articulador. A sua função principal é de orientar a aprendizagem dos alunos - uma aprendizagem que se desenvolve na interação colaborativa entre formadores, formador, especialistas e outros envolvidos, propiciando a criação de uma rede de comunicação e colaboração, na qual todos se inter-relacionam.
Em outras palavras, os professores de educação a distância assumem papéis que extrapolam a mera orientação pedagógica dos alunos. As experiências vivenciadas e relatadas por Almeida e Prado (2003), em um curso totalmente a distância, mostraram a relevância e a necessidade da criação de uma cultura de EaD fundamentada na interação e na colaboração entre os sujeitos do curso. No contexto do ambiente de aprendizagem colaborativa, ${ }^{7}$ os novos conhecimentos são construídos pelo grupo, de forma coletiva, e as práticas pedagógicas e experiências cotidianas de sala de aula dos alunos são refletidas e socializadas no e para o grupo, a fim de se reelaborar o conhecimento no coletivo.

$\mathrm{Na}$ perspectiva da aprendizagem colaborativa, segundo Almeida e Prado (2003, p. 76), há um rompimento da concepção de que o professor detém a tarefa de transmitir as informações, solicitar tarefas e definir caminhos a serem seguidos. Nesse modelo de aprendizagem, o papel do professor passa a ser o "de orientador e principalmente de parceiro na aprendizagem e novas descobertas, respeitando as idéias e estilos de trabalho dos alunos".

Almeida (2003, p. 77) destaca que a característica peculiar do desenvolvimento e do ritmo das atividades de um curso totalmente a distância exige dos professores e do coordenador uma postura de abertura, flexibilidade e compreensão para aprender e desenvolver um plano de atividades que dê não apenas uma direção no ambiente virtual, mas também permita - a partir dos registros textuais presentes nas diversas ferramentas do ambiente virtual, como fóruns, webfólios, chats uma reformulação coerente com a realidade e necessidade dos alunos.

Um papel secundário do fórum on-line é o de permitir que as mensagens sejam postadas em seu espaço interno; seus ícones e funções devem possibilitar as operações dos sujeitos e a execução das tarefas solicitadas. Nesse caso, ele tem também a função de uma biblioteca, de um comunicador onde se postam e armazenam as mensagens, as discussões, os debates ou os objetos para serem utilizados a qualquer momento do curso. Suas características devem ser de simplicidade e funcionalidade, para que não ocorram falhas no envio de uma mensagem ou falhas no acesso, em qualquer tempo, de qualquer um dos sujeitos envolvidos nesse ambiente.

\footnotetext{
A aprendizagem colaborativa é definida por Palloff e Prat (2004, p. 58) a partir da definição de atividade colaborativa. Para esses autores, "a atividade colaborativa em um curso on-line - seja por meio de projetos feitos em grupos pequenos, simulações, trabalhos com estudos de casos ou outros métodos - é provavelmente a melhor maneira de abranger todos os estilos de aprendizagem do grupo".
} 
O processo de ensino e aprendizagem em cursos a distância pode ser implementado a partir das interações sociais que ocorrem nas situações didáticas planejadas para o fórum. É indispensável que o professor as prepare e que o fórum não seja apenas um repositório de informações a ser utilizado pelos sujeitos que buscam o conhecimento.

Neste artigo objetivou-se discutir o papel do fórum on-line em um curso a distância, bem como as concepções de fórum dos professores que participaram do estudo de caso. Este estudo percorreu caminhos que permearam as análises sobre a utilização do fórum on-line pelos professores e alunos, a partir das investigações dos problemas e dificuldades no uso desse meio, e o levantamento das concepções dos professores acerca do papel desse artefato.

A pesquisa tratada neste artigo teve como base teórica as idéias de Brousseau (1996) a respeito das situações didáticas e do contrato didático e as noções de interação de Vigotsky (2000). No que tange aos aspectos da formação do professor de EaD apresenta-se uma breve discussão das idéias discutidas por Belloni (2001), da formação de comunidades de aprendizagem on-line, do papel do professor e do aluno virtual de Palloff e Pratt (2004), e sobre os conceitos de ambientes de aprendizagem digital de Almeida (2003).

\section{A formação do professor de EaD}

$\mathrm{Na}$ abordagem construtivista, o processo de aprendizagem é analisado levando-se em conta a difícil questão a ser superada pelo professor: a de encontrar um equilíbrio entre a quantidade de informação acumulada e a forma de apreensão desse conhecimento por parte do aluno equilíbrio no sentido de optar por um conhecimento que tenha significado para o aluno em detrimento da quantidade exigida nos currículos das escolas.

A formação do professor, no contexto da teoria de situação didática (Brousseau, 1996, apud Silva, B., 2002), deve ser orientada para uma prática baseada no conhecimento do aluno. A situação didática discutida por Brousseau (1996, apud Chevallard, 2001, p. 217) compreende "as relações estabelecidas explícita ou implicitamente entre os alunos, um determinado meio (que inclui instrumentos e objetos) e o professor, com o objetivo de que os alunos aprendam o conhecimento".

Para que a aprendizagem se realize nas diferentes situações didáticas, algumas regras devem ser observadas e respeitadas. Essas regras são estabelecidas no Contrato Didático.

Chama-se contrato didático o conjunto de
comportamentos do professor que são es-
perados pelos alunos e o conjunto de com-
portamentos do aluno que são esperados
pelo professor [...]. Esse contrato é o con-
junto de regras que determinam uma pe-
quena parte explicitamente mas sobretu-
do implicitamente, o que cada parceiro da
relação didática deverá gerir e aquilo que,
de uma maneira ou de outra, ele terá de
prestar conta perante o outro (Brousseau,
1986, apud Silva, B., 2002, p. 43-44).

São as regras do contrato didático que permitem aos sujeitos da situação, professores e alunos, interagirem com o objeto de aprendizagem - o conhecimento - através de um meio preparado pelo professor, que é o organizador das ações de todos os sujeitos envolvidos nessa situação. Segundo Chevallard (1988, apud Silva, B., 2002, p. 60-61),

O contrato didático reúne (criando-os como tal) três termos (três instâncias) e não duas como se acredita algumas vezes. O aluno (o sujeito a quem se ensina), o professor (o sujeito que ensina) e o saber, considerado como o "saber ensinado". O contrato rege, portanto, a interação didática entre professor e alunos a propósito do saber [...] as cláusulas do contrato organizam as relações que os alunos e professores mantêm com o saber.

O contrato didático, segundo Chevallard (2001), apresenta alguns paradoxos em função de duas ocorrências:

1) O aluno pode realizar a aprendizagem quando obtém o sucesso, quando ele assume a responsabilidade de resolver certos problemas dos quais não lhe ensinaram a solução.

2) O aluno se revolta porque não sabe resolver o problema, e o professor se surpreende porque considera suas explicações suficientes. 
As insatisfações de ambos, professor e aluno, levarão à ruptura do contrato didático gerando uma crise na relação, o que provocará a renegociação de um novo contrato e a busca de um novo conhecimento. A crise e a busca do conhecimento pela ruptura contribuem para a aprendizagem. Chevallard (2001, p. 219) afirma: "a aprendizagem não repousa, na verdade, sobre o bom funcionamento do contrato, mas sobre suas rupturas".

Ressalta-se, entretanto, que

[...] Contratos didáticos mal-adaptados ou mal-compreendidos podem originar muitos mal-entendidos e a sensação, por parte dos alunos, de terem sido enganados. [...] Esses descontentamentos podem gerar recusas ou, até mesmo, verdadeiros fracassos escolares.” (Silva, B., 2002, p. 63).

Um outro conceito importante a ser considerado pelo professor que atua em $\mathrm{EaD}$ é o de interação, que será discutido com base nas idéias sociointeracionistas de Vigotsky (2001b, apud Facci, 2004, p. 184):

O próprio aluno se educa [...] não cabe ao professor educar [...], ele tem que levar o aluno a pensar nesses conhecimentos [...], o professor é o organizador do meio social educativo, é ele quem regula e controla a sua interação com o educando.

É responsabilidade do professor organizar um meio com dificuldades a serem superadas por seus alunos. O professor deve possuir um amplo conhecimento científico sobre o meio e o domínio do conteúdo de sua disciplina num contexto de desenvolvimento das ciências.

A tarefa do professor é ensinar ao aluno aquilo que ele não consegue desenvolver por si mesmo; suas ações de orientação são mediadoras entre o aluno e os conceitos científicos, resultando a formação dos processos psicológicos superiores no indivíduo.

Vigotsky (2000) defendeu que a experiência socioistórica é relevante para o aluno desenvolver seus processos psicológicos superiores. Ou seja, é importante que o aluno receba na escola o conhecimento das experiências socioistóricas, a fim de que ele transforme seu próprio conhecimento e desenvolva seus processos cognitivos. Os resultados das pesquisas de Vigotsky (2000) mostraram que o indivíduo elabora melhor o pensamento acerca de um problema, de modo mais rigoroso, analítico e lógico, quando numa situação coletiva - de interação social - em que é acompanhado ou ajudado por uma pessoa mais experiente. Enfatiza-se, também, a importância do aspecto afetivo na interação professor-aluno e no desenvolvimento do sistema psíquico do indivíduo, onde o ensino escolar tem papel básico.

As interações coletivas vivenciadas no fórum do curso a distância se constituem focos de interesses, dentro das idéias que embasam as análises das comunicações pela linguagem, e favoreceram o entendimento pedagógico e a construção dos processos cognitivos dos alunos.

Além das teorias discutidas, apresenta-se uma discussão sobre as características principais do perfil do professor de educação a distância baseada nas idéias de Belloni (2001), de Palloff e Pratt (2004) e de Almeida (2003). As características e singularidades que definem tal professor estão sendo, ainda, estabelecidas na conjuntura global e de transição pela qual esse profissional passa.

\section{O perfil do professor de EaD}

Os professores inseridos na realidade da EaD são, em geral, profissionais formados no ensino presencial. Em alguns casos eles possuem, além dessa formação, experiências e participações em cursos de atualização ou especialização em EaD, o que os tornam mais bem preparados para atuar na docência a distância.

A EaD exige do professor, além daquelas atitudes e ações necessárias de um profissional de educação, um ajuste fundamental em seus planejamentos de atividades, nos seus conceitos de espaço e de tempo, e de suas concepções de curso a distância.

Até meados de 90 havia em relação a EaD uma "indefinição conceitual e institucional" que influenciava as funções e atuações do professor (Marsden, 1996, apud Belloni, 2001, p. 79). Hoje, embora ela faça parte das ofertas de várias empresas, universidades, escolas e centros de treinamento, o professor ainda não tem um papel definido e desempenha várias funções, para muitas das quais ele não foi preparado. Belloni (2001) reuniu essas funções em três grupos: 
1) responsabilidade de criar cursos e materiais;

2) gerenciamento do planejamento, da organização, da administração acadêmica (matrícula e avaliação), bem como a distribuição de materiais; e

3) acompanhamento do aluno no processo de aprendizagem (tutoria, acompanhamento e avaliação).

Belloni (2001, p. 84-85) comenta que as dificuldades de integração dos três grupos de funções são vivenciadas por professores que atuam ou que já atuaram pelo menos uma vez na EaD. Ela afirma que a criação do cargo de "Tecnólogo Educacional” veio para resolver esses problemas, uma vez que esse profissional tem o papel de garantir a "transposição do discurso escrito do professor/autor para as linguagens adequadas aos suportes técnicos".

Seja na EaD ou no ensino presencial, Belloni (2001) considera que a formação do professor deve contemplar três dimensões fundamentais: a pedagógica, a tecnológica e a didática.

Contribuindo também para a construção de um perfil próprio do professor de EaD, Palloff e Pratt (2004, p. 39) observam que "o papel e a presença do professor são fundamentais na formação da comunidade de aprendizagem on-line".

Uma das principais características, apontadas por esses autores, que o professor de EaD deve ter, é a competência de ampliar a interação no ambiente on-line ao máximo: "Incentivar a discussão assíncrona é a melhor maneira de sustentar a interatividade de um curso on-line." Para eles, o professor de EaD pode manter a interação através de perguntas amplas no sentido de alcançar um equilíbrio entre a interação excessiva e a interação insuficiente. Ressaltam a importância de os professores de EaD apresentarem uma boa participação na comunidade de aprendizagem on-line. O professor responsável pela aprendizagem nessa comunidade deve conectar-se com freqüência ao grupo e contribuir para a discussão e formação da comunidade (Palloff, Pratt, 2004, p. 47-48).

Entre outros papéis, Almeida (2003) menciona "acompanhar o aluno em seu desenvolvimento no curso, o estar junto virtual”, com uma função de orientar o aluno, “provocá-lo no sentido de fazê-lo refletir, compreender os equívocos e depurar suas produções”. Entretanto, isso não significa que o professor estará on-line 24 horas ou sempre que o aluno precisar; embora se faça presente no ambiente do curso com freqüência, ele não está no ambiente com o objetivo de controlar o aluno ou o seu desempenho - isso significaria um retrocesso para um ambiente digital de aprendizagem. Ainda para esse autor, no ambiente digital de aprendizagem há uma sofisticação que exige do aluno certa autonomia e uma quebra da relação de dependência do aluno, característica de "uma abordagem de ensino que em algumas situações tradicionais já se mostraram inadequadas e ineficientes" (Almeida, 2003, p. 5).

A formação esperada do professor é aquela que desenvolva, também, competências em direção a uma prática pedagógica reflexiva, em que teoria e prática se aliem, e que lhe dê autonomia na aplicação dos saberes, possibilitando a concepção, planejamento e promoção de práticas pedagógicas específicas a $\mathrm{EaD}$.

\section{Metodologia}

A metodologia utilizada foi a da pesquisa qualitativa, do tipo estudo de caso. O fórum on-line do curso pesquisado foi desenvolvido por uma equipe de dois professores do próprio curso, sendo um deles o coordenador na primeira edição do curso e o outro, designer educacional, webdesigner e web-master, entre outros papéis a ele atribuídos e confirmados em seus depoimentos na entrevista. Este utilizou, para a criação do fórum, ferramentas desenvolvidas em software livre, entre elas o sistema operacional Linux, o banco de dados Mysql e o processador de scripts PHP. Os scripts do fórum tiveram como base o $w$-Agora,$^{8}$ um sistema de publicação e gerência de fórum na $w e b$.

O curso foi oferecido com dez disciplinas disponibilizadas no ambiente on-line duas a duas para cada período de dois meses, de acordo com o calendário divulgado no início do curso. Nos períodos de férias (julho, dezembro e janeiro) houve uma variação na quantidade de disciplinas: foram disponibilizadas três disciplinas por período.

Elaborou-se um fórum on-line para cada disciplina do curso. A disponibilidade agosto de 2006 . 
dos conteúdos das disciplinas no ambiente on-line ocorreu simultaneamente à abertura de seus fóruns. A primeira aula de cada disciplina foi presencial, conforme o calendário do curso, e ocorreu um dia após a apresentação dos conteúdos no ambiente on-line.

Após o término da disciplina, previsto no calendário, os alunos tinham mais 30 dias, conforme as regras implícitas no contrato didático, para postar no fórum todas as atividades e trabalhos de conclusão da disciplina.

Os dados da pesquisa foram coletados nas entrevistas com os professores, alunos e coordenador do curso, nas informações obtidas nos fóruns das disciplinas e na pesquisa documental.

As observações do ambiente foram realizadas acessando-se os fóruns via Internet e tomando-se notas das participações, o que ocorreu até o final de junho de 2005, quando se fechou o oferecimento das disciplinas. No período de setembro de 2004 a abril de 2005 foram realizadas as entrevistas com os professores em concomitância com as observações dos fóruns, tendo essas se estendido até junho de 2005.

A freqüência das observações diminuiu em função do término das disciplinas e da conseqüente diminuição das interações no fórum. Verificou-se que apenas três fóruns fecharam o recebimento de mensagens após o período de 30 dias de encerramento. Nos demais, em dois fóruns não houve fechamento, apenas uma diminuição na quantidade de interações conforme a dinâmica do professor e do próprio fórum, e cinco foram mantidos ativos por mais de dois meses, mas os professores não participaram, isto é, não mais postaram atividades ou respostas às dúvidas. Houve, também, reduzido número de mensagens durante o período de funcionamento da disciplina.

Para as entrevistas com os professores, elaborou-se um roteiro contendo 10 questões abertas pertinentes ao uso do fórum. Dez professores do curso foram entrevistados; cada um deles era responsável por uma disciplina e seu respectivo fórum. Desses, um foi entrevistado duas vezes, por acumular os cargos de professor e coordenador do curso.

Para a tabulação dos dados, os professores foram organizados por letras do alfabeto, de A a J, mantendo-se assim o sigilo das informações e o respeito aos docentes investigados.

O tratamento dos dados ocorreu a partir das análises detalhadas das respostas de cada professor, seguida por uma análise geral e pelo cruzamento dos resultados das questões.

Neste artigo são apresentadas as análises dos dados de cinco questões das entrevistas com os professores e nos dados de uma questão da entrevista com os alunos, em razão do recorte que se fez, visando levantar as concepções de fórum on-line dos professores. A entrevista com os alunos foi realizada mediante um questionário contendo 10 questões do tipo semi-estruturado, aplicado aos 53 alunos durante o seminário presencial da disciplina "Recursos Didáticos em EaD”, no mês de outubro de 2004. Trinta e dois devolveram os questionários respondidos.

\section{Análises e resultados}

Para levantar as concepções acerca do papel do fórum on-line na visão dos professores do curso pesquisado, foram analisadas apenas algumas questões das entrevistas dos professores e alunos. Foram acrescentadas a essas análises as informações obtidas na observação do fórum de cada disciplina, obtendo-se assim informações que possibilitaram estabelecer uma comparação entre as concepções desses professores a partir dos seus depoimentos e de suas respectivas participações (práticas pedagógicas).

\section{Análises dos resultados das entrevistas com os professores}

Serão apresentadas as análises relativas às questões $1,2,5$ e $8 \mathrm{da}$ entrevista realizada com os professores, por acreditar-se que essas questões subsidiam a investigação acerca das concepções desses professores sobre o papel do fórum on-line.

Na primeira questão - "Você já fez uso do fórum em outras disciplinas?” - , os resultados mostraram que dois professores não haviam utilizado o fórum antes do curso. Esses docentes não tinham experiências no uso do fórum, e a formação relacionada com a dimensão tecnológica 
necessária, em particular do uso desse recurso, não estava contemplada.

Segundo Belloni (2001), a formação dos professores de EaD deve ocorrer nas três dimensões fundamentais: pedagógica, didática e tecnológica. O fato de dois docentes sem experiência no uso do fórum on-line terem sido selecionados para atuarem no curso pode ser interpretado por duas vias: ou a seleção priorizou outros aspectos da formação desses docentes ou não houve critério quanto à exigência de experiência em ambientes on-line como pré-requisito para a seleção. Problemas dessa natureza podem ser remediados se a organização do curso oferecer uma capacitação que contenha em seus conteúdos não apenas o desenvolvimento da habilidade para trabalhar com tecnologias de informação, mas também uma reflexão sobre o papel desses artefatos, neste caso o fórum, e a relevância da participação do docente para incentivar e proporcionar a interação nesse ambiente (Palloff, Pratt, 2004). Caso contrário, a capacitação é inócua e pode reproduzir uma concepção inadequada de uso do ambiente on-line.

Na segunda questão - "Você teve dificuldades ou venceu falhas na utilização do fórum?” -, sete dos dez professores disseram que encontraram dificuldades. Entre os que responderam afirmativamente, observou-se que dois não utilizaram o fórum on-line durante todo o curso; os outros cinco postaram mensagens. Quanto aos três que afirmaram não enfrentar dificuldades, verificou-se um reduzido número de mensagens nos fóruns de suas respectivas disciplinas.

A análise das duas primeiras questões (questões 1 e 2) mostrou que, embora oito tenham afirmado que já haviam utilizado o fórum, apenas três afirmaram não encontrar dificuldades. Verificou-se, pela observação do ambiente e pelas respostas nas entrevistas, que nove professores não dominavam o uso do fórum, isto é, não se encontravam preparados para utilizar o fórum on-line no curso pesquisado. Apenas uma professora manteve interações envolvendo réplica e tréplica em seu fórum, embora ela também tenha encontrado dificuldades.

Segundo Palloff e Pratt (2004, p. 47), o professor deve estimular a participação do aluno no ambiente on-line buscando "sustentar a interatividade do curso on-line". Para a maioria dos professores observados, a interatividade não foi sustentada, e no fórum de um professor não houve qualquer interação.

Foram observadas mensagens de alunos reclamando da falta de respostas de alguns professores às suas dúvidas. A falta de interações sugere que esses professores desconhecem as potencialidades do fórum on-line. Essa ausência de mensagens do professor evidencia um descumprimento do contrato didático (Chevallard, 1988, apud Silva, B., 2002) e reforça a concepção de que o fórum serve apenas para o aluno postar ali suas atividades ou tarefas.

Os professores partidários da concepção de que o fórum é apenas um meio a mais de comunicação com os alunos não sentem dificuldades no uso desse artefato.

Para aqueles que admitiram encontrar dificuldades - sete professores, um dos quais não trocou mensagens - , observou-se que as dificuldades estavam relacionadas à falta de familiaridade de alguns professores com esse tipo de ferramenta, à concepção de fórum como uma ferramenta apenas de comunicação, à concepção equivocada ao confundir o chat com o fórum e até mesmo à falta de conhecimento sobre o funcionamento desse ambiente, como foi observado na atitude de um dos dois professores que não chegaram a postar sequer uma mensagem em seu fórum. Um destes, ao ser questionado na entrevista por que não havia dado retornos aos seus alunos, respondeu: "Ah, já vou logo te avisando, eu não tenho aberto o fórum porque ele só abre lá na coordenadoria de educação a distância” (Entrevista, Professor G, 1\%/4/05). A dificuldade apresentada por esse professor mostrou uma concepção equivocada de fórum, além de um certo descaso para com o curso e para com os alunos, caracterizando, também, uma ruptura do contrato didático (Chevallard, 1988, apud Silva, B., 2002). Mostrou ainda desconhecer as características de um ambiente de curso online, bem como sua assincronicidade (Palloff, Pratt, 2004). O outro professor que não interagiu no fórum, ao ser questionado por que ainda não havia trocado mensagens no fórum, respondeu que teve problemas particulares (doenças) com a família. A falha desse professor, que não foi suprida pela coordenadoria, evidenciou dificuldades por parte da coordenação do curso.

Uma outra dificuldade observada estava relacionada com o fórum da coordenadoria; mensagens de professores 
e de alunos foram postadas para o fórum da coordenadoria contendo dúvidas e reclamações que não foram respondidas. Esse fato evidenciou algumas falhas na organização do curso, bem como concepções inadequadas de utilização do fórum, uma vez que o regulamento do curso não apresentou políticas (diretrizes e normas) definidas de utilização, no sentido de estabelecer um termo de compromisso que explicitasse as funções do professor e que assegurasse seu compromisso de dar retornos nos fóruns (interagir com os alunos) durante todo o período de utilização do meio ou de vigência do curso. Os fóruns que tiveram as mensagens neles postadas e não foram respondidas receberam reclamações dos alunos (também enviadas para o fórum da coordenação); isto, porém, não resultou em medidas, por parte da coordenação, que garantissem o direito do aluno. $\mathrm{Na}$ realidade, esses compromissos foram considerados nas regras implícitas do contrato didático de cada disciplina.

A coordenação do curso deve ser preparada para o gerenciamento do planejamento, da organização, da administração acadêmica e do acompanhamento do aluno no processo de aprendizagem. Considerando-se que o fórum é o meio pelo qual os alunos interagem com o professor e entre si, na ausência do professor, como um agente "provocador" dessa interação, caberia à coordenação providenciar uma tutoria que acompanhasse os diversos fóruns (Belloni, 2001).

As dificuldades observadas na utilização do fórum ao longo do curso e as informações obtidas nas entrevistas com os professores evidenciaram que tanto os professores quanto os conceptores do curso compartilham da concepção de fórum como uma ferramenta de comunicação, um repositório de atividades, o que poderia, em parte, justificar a postura da coordenação e de alguns professores.

$\mathrm{Na}$ quinta questão - "Na sua opinião, qual a importância do fórum com relação às outras formas de interação (e-mail, chat, blog, lista de discussão, etc.) com o aluno?" -, sete professores consideraram o fórum um recurso que permitiu maior interação em relação ao e-mail, chat, lista de discussão e blog. Dos três restantes, um afirmou que o fórum contribuiu para a interação tanto quanto qualquer outro recurso, tendo ressaltado que essa interação depende do professor. O outro deu resposta não conclusiva e o terceiro afirmou que o fórum permite o compartilhamento das informações, considerando o chat o recurso que permitiu maior interação.

A análise da questão 5 mostrou que, para a maioria (sete professores), o fórum é um recurso que permite o maior grau de interação com os alunos no ambiente on-line em relação aos outros recursos existentes no meio, tais como o e-mail, lista de discussão, chat e outros. Entretanto, a observação das práticas dos professores no fórum de suas disciplinas mostrou que esses sete professores não estavam preparados para a utilização do fórum, porque suas mensagens de retorno aos alunos não foram suficientes para estabelecer uma boa interação no ambiente (Palloff, Pratt, 2004). Eles demonstraram reconhecer a importância do recurso, mas não o utilizaram corretamente porque desconheciam todas as suas potencialidades. Esse reconhecimento ficou evidenciado no depoimento da professora D: "Porque a gente usa com muitas limitações. [...] falta um treinamento especial, tanto dos professores, quanto dos alunos, quanto dos técnicos dos setores que trabalham pela coordenadoria" (Entrevista, Professora D, 23/12/04).

Esse fato também evidenciou um despreparo geral dos sujeitos envolvidos no curso; eles não se mostraram habilitados para utilizar esse recurso como um ambiente de interação e colaboração para promover a aprendizagem. Evidencia-se nessa análise a necessidade de formar professores com competências que abranjam as três dimensões mencionadas por Belloni (2001): a pedagógica, a didática e a tecnológica, conforme apontado no depoimento da professora citada, além daquelas discutidas por Almeida (2003) e Palloff e Pratt (2004).

Na questão 8 - "Como foi a sua interação no fórum?” -, as formas de interação apresentadas foram classificadas em nove categorias para fins de análise. A análise dos resultados mostrou que três professores interagiram de forma não satisfatória no fórum, isto é, apenas para a postagem das atividades, tendo deixado de responder mensagens com dúvidas e solicitações de alguns alunos no fórum, e dois não utilizaram esse recurso. Um professor utilizou o fórum para provocar discussões, debates, e apresentou réplica e tréplica às questões debatidas pelos alunos, e quatro utilizaram-no para postagem das atividades 
e dúvidas e estimularam a interação dando retornos aos questionamentos enviados.

Comparando-se a análise da questão $8 \mathrm{com}$ as das duas primeiras (as questões 1 e 2), evidencia-se novamente que a alegada experiência de utilização do fórum não garantiu, em suas práticas pedagógicas, uma utilização de fórum coerente com a necessidade de interação que caracterizasse uma aprendizagem colaborativa. Em outras palavras, embora a maioria dos professores tenha afirmado que já havia utilizado o fórum, eles não usufruíram as potencialidades desse meio como um ambiente de aprendizagem nessa modalidade de educação e apresentaram, na prática, uma concepção de fórum apenas como um recurso comunicacional.

Esses professores não buscaram manter o interesse dos alunos com interações assíduas no ambiente on-line, como recomendam Palloff e Pratt (2004).

A análise em conjunto dos resultados das questões 2, 5 e 8 demonstrou que, no geral, embora eles reconheçam que esse meio possibilita maior grau de interação em relação aos outros recursos, o reduzido número de mensagens postadas no fórum e, conseqüentemente, a pouca interação apresentada pela maioria dos professores são evidências de que o fórum foi um recurso utilizado de forma inadequada no curso em estudo.

Esses resultados mostraram, ainda, que a falta de uma interação mais efetiva pela maioria dos professores proporcionou uma ruptura do contrato didático, levando alguns estudantes a usar outros meios (o uso do telefone e reunião presencial com a coordenação) para buscar respostas aos seus problemas de interação no fórum online, bem como reclamar da participação de alguns professores que não interagiram. Embora Chevallard (2001) afirme que a ruptura do contrato pode resultar em aprendizagem, Silva, B. (2002) argumenta que essa ruptura pode, também, levar a verdadeiros fracassos escolares.

\section{Análise de um resultado das entrevistas com os alunos}

Para complementar a análise sobre as concepções dos professores foi escolhida apenas a questão 7 do questionário solicitado aos alunos.
A questão solicitada foi " $\mathrm{Na}$ sua opinião, o fórum contribui para a interação entre professor e aluno?" Dos 32 alunos que responderam, 24 afirmaram que o fórum on-line contribuiu bastante, sete alunos, que a contribuição do fórum foi pouca, e para um aluno não houve contribuição do fórum na interação com o professor.

A análise da questão sete mostrou que, embora 31 alunos tenham considerado vantajosa a utilização do fórum, as interações observadas no ambiente foram reduzidas, e apenas dois professores deram retornos freqüentes.

$\mathrm{O}$ fato de 31 alunos afirmarem que o fórum contribuiu para a aprendizagem mesmo tendo sido observada a reduzida interação, na maior parte dos fóruns, com os professores e até mesmo com os outros alunos - mostra que os alunos também desconhecem o seu papel e a sua responsabilidade em colaborar e gerenciar o processo de aprendizagem na condição de mantenedores e formadores de uma comunidade de aprendizagem on-line, conforme afirmam Palloff e Pratt (2004).

Uma concepção de uso do fórum também inadequada foi mostrada por um aluno, que negou a contribuição do fórum justificando que a interação não aconteceu porque o professor não deu retorno no fórum. Embora tenha declarado que não houve interação no fórum, ele não cobrou dos professores uma boa resposta nem exigiu uma solução por parte da instituição; essa ausência de exigência mostra o desconhecimento do seu papel no fórum ou a sua frustração pela falta de objetivo no curso.

Para Strong e Harmon (1977, apud Palloff, Pratt, 2004, p. 73-74), os alunos de um programa a distância procuram cursos que tenham, entre outras características, foco no aluno e não no professor, bom custo-benefício, ambiente tecnológico confiável, fácil navegação e "níveis adequados de informação e interação humana”. Palloff e Pratt (2004) argumentam ainda que, se esses alunos não se sentem atendidos, eles podem ficar frustrados e desistir do programa ou do curso.

A falta de autonomia para debater, no fórum, a ausência das mensagens do professor mostrou que, de um modo geral, os professores não criaram uma comunidade de aprendizagem on-line e que os alunos também desconheciam suas atribuições de colaboradores no sentido de provocar a 
interação entre eles mesmos, porque houve uma falta de "mensagens de apoio dos próprios alunos entre si, além da falta de mensagens dirigidas de um aluno a outro que pudesse evidenciar uma aprendizagem colaborativa” (Palloff, Pratt, 2004, p. 39).

$\mathrm{O}$ fato de alguns alunos não terem recebido retornos significativos do professor, mesmo tendo 24 deles afirmado que o fórum contribuiu para o alcance dos seus objetivos, mostra que esses alunos compactuam com uma prática reprodutivista do modelo presencial, em que não há cobranças de ambas as partes.

\section{Conclusões}

Concluiu-se que as dificuldades na utilização do fórum on-line na EaD têm sido inúmeras, abrangendo não somente professores como também alunos, no âmbito da pesquisa desenvolvida junto à instituição pública de ensino superior. Os recursos tecnológicos nela utilizados, embora se constituam meios eficientes e potenciais, não têm garantido a necessária interação em face do despreparo dos professores e de suas concepções inadequadas de uso do fórum on-line, caracterizando, mais uma vez, uma concepção de fórum como repositório de atividades e não reconhecendo nesse ambiente um importante recurso para a interação e construção coletivas do conhecimento através da aprendizagem colaborativa.

A maioria dos professores apresentou um perfil que se enquadra em uma ou outra das três dimensões identificadas por Belloni (2001). Uma formação continuada e específica para atuar na EaD, principalmente no que se refere ao uso do fórum on-line, merece destaque e certamente poderia contribuir para a melhoria na qualidade dessa modalidade de ensino.

Esses resultados devem contribuir para fomentar discussões que favoreçam a construção de modelos de curso de EaD, com propostas metodológicas específicas para essa modalidade de ensino e que potencialize o uso dos artefatos tecnológicos; neste caso os recursos da informática, em particular do fórum online, no sentido de contribuir para a mudança das atuais concepções desse meio, entre os professores que atuam em cursos a distância.

Finalmente, conclui-se que as concepções de fórum, por parte dos professores do curso investigado, são oriundas de formação e práticas presenciais, e que há poucos incentivos para atualização permanente desses profissionais. Esses resultados sugerem a necessidade de investimentos por parte das políticas públicas na formação continuada dos professores de EaD, que levem em consideração as dificuldades levantadas pelos professores no estudo realizado e que contribuam para mudanças de suas concepções. Podem também contribuir no sentido de destacar e promover o desenvolvimento de novas pesquisas que venham a apontar soluções para antigos e novos problemas e de propor diretrizes nessa modalidade de educação.

\section{Referências bibliográficas}

ALMEIDA, M. E. B. Educação a distância na Internet: abordagens e contribuições dos ambientes digitais de aprendizagem. Revista Educação e Pesquisa, v. 29, n. 2, p. 327340, jul./dez. 2003. .

ALMEIDA, M. E. B.; PRADO, M. E. B. B.; VALENTE, J. A. (Org.). Educação a distância via Internet. São Paulo: Avercamp, 2003.

BARSOTTI, C. As Interfaces como Artefatos Mediadores e sua Evolução em um Programa de Leitura em Língua Inglesa a Distância. 2002. 145 f. Dissertação (Mestrado em Tecnologia) - CEFET-PR, Curitiba, 2002. Disponível em: < http://www.ppgte.cefetpr.br/ dissertacoes/2002/barsotti.pdf> Acesso em: 8 jun. 2005.

BELLONI, M. L. Educação a distância. Campinas: Autores Associados, 2001. 
CHEVALLARD, Y. Estudar Matemáticas: o elo perdido entre o ensino e a aprendizagem. Tradução de Daisy Vaz de Moraes. Porto Alegre: Artmed, 2001.

FACCI, M. G. D. Formação de professores: valorização ou esvaziamento do trabalho do professor: um estudo crítico-comparativo da teoria do professor reflexivo, do construtivismo e da psicologia vigotskiana. Campinas: Autores Associados, 2004.

FERREIRA, A. B. H. Novo Aurélio: o dicionário da língua portuguesa. 5. impressão. Rio de Janeiro: Nova Fronteira, 1999.

HOUAISS, A. Dicionário da Língua Portuguesa. 2. ed. rev. amp. Rio de Janeiro: Moderna Ltda., 2004.

MORAN, J. M. Propostas de mudanças nos cursos presenciais com a educação on-line. Texto apresentado no $11^{\circ}$ Congresso Internacional de Educação a Distância. Disponível em: http://www.eca.usp.br/prof/moran/propostas.htm\#utilização. Acesso em: 26 jul. 2006.

Contribuições para uma pedagogia da educação on-line. In: SILVA, M. (Org.). Educação on-line: teoria, práticas, legislação, formação corporativa. São Paulo: Loyola, [s.d.]. p. 39-50. Disponível em: http://www.eca.usp.br/prof/moran/contrib.htm\#gestao. Acesso em: 25 jul. 2006.

PALLOFF, R. M.; PRATT, K. O aluno virtual: um guia para trabalhar com estudantes on-line. Tradução de Vinicius Figueira. Porto Alegre: Artmed, 2004.

SILVA, B. A. Contrato didático. In: MACHADO, S. D. A. Educação matemática: uma introdução. $1^{\mathrm{a}}$ reimpressão. São Paulo: PUC-SP, 2002. p. 43-64.

SILVA, L. H. A. Modos de mediação de um formador de área científica específica na constituição docente de futuros professores de Ciências/Biologia. 2004. 129 f. Tese (Doutorado em Educação) - Universidade Metodista de Piracicaba, Piracicaba, 2004.

SILVA, M. Sala de aula interativa. Disponível em: http://www.saladeaulainterativa.pro.br/ forum_apres.htm. Acesso em: 25 jul. 2006.

VIGOTSKY, L. S. A formação social da mente: o desenvolvimento dos processos psicológicos superiores. Tradução de José Cipolla Neto. São Paulo: Martins Fontes, 2000.

. Pensamento e linguagem. Tradução de Jefferson Luiz Camargo. Revisão técnica

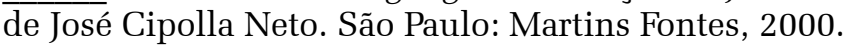

Shirley Takeco Gobara, doutora em Didática de Disciplinas Científicas pela Université Claude Bernard - Lyon I (FR), é professora permanente do Programa de PósGraduação em Educação e coordenadora da Comissão de Estágio Supervisionado (Coes) do curso de Licenciatura em Física do Departamento de Física (CCET) da Universidade Federal de Mato Grosso do Sul (UFMT).

gobara@dfi.ufms.br

Erlinda Martins Batista, mestre em Educação pela Universidade Federal de Mato Grosso do Sul (UFMS), é técnica de tecnologia da informação na Coordenadoria de Educação Aberta e a Distância e professora do curso de Pedagogia da UFMS.

ebb@nin.ufms.br

Recebido em 17 de abril de 2006.

Aprovado em 30 de agosto de 2006. 